\section{ECCOMAS}

COMPDYN 2021

$8^{\text {th }}$ ECCOMAS Thematic Conference on Computational Methods in Structural Dynamics and Earthquake Engineering

M. Papadrakakis, M. Fragiadakis (eds.) Streamed from Athens, Greece, 28 - 30 June 2021

\title{
NUMERICAL PARAMETRIC STUDY OF GRILLE-TYPE STEEL CONCRETE COMPOSITE SHEAR WALL FOR SEISMIC REGIONS
}

\author{
Tian Wang ${ }^{1}$, Qiao Yu ${ }^{2 *}$, Hao Wu ${ }^{2}$, Yang Liu ${ }^{1}$, Lingzhi Li $^{2}$, Xianlong Zhang ${ }^{1}$ \\ ${ }^{1}$ China Construction Seventh Engineering Division (Shanghai) Corp. Ltd. \\ 235 E. Yunling Rd., Putuo District, Shanghai 200062, China \\ 1109974324@qq.com, liuyang10@cscec.com,1091370813@qq.com \\ ${ }^{2}$ College of Civil Engineering, Tongji University \\ 1239 Siping Rd., Shanghai 200092, China \\ yq_@tongji.edu.cn,2009wuhao_tom@tongji.edu.cn, lilingzhi@tongji.edu.cn
}

\begin{abstract}
Grille-type steel plate concrete composite shear wall (GSPCW) is an innovative shear wall system consisting of steel faceplates, steel tie plates and infilled concrete. Compared with traditional steel plate concrete composite shear wall, GSPCW has the following advantages: 1) high buckling resistance, and 2) simple structural measures and convenient construction. This paper presents a numerical study of the GSPCW using DIANA software and comprehensively investigates the influence of varying design parameters on the seismic performance. First, DIANA models are established for considered GSPCW specimens and validated through comparing numerical results with previous test data. The verified model is further used to perform a parametric study to understand the influence of several design variables on seismic behavior of GSPCW, including steel ratio, axial load ratio, height-width ratio, aspect ratio of grille as well as concrete compressive strength. Results indicate that the former four parameters have remarkable impacts on seismic behavior of GSPCW: 1) The load and deformation capacity of a GSPCW increase significantly as the steel ratio increase; 2) The load capacity and ductility increase to a certain degree with increase of axial load ratio, however excessively high axial load ratio may have a negative impact on ductility behavior; 3) The load capacity and stiffness of a GSPCW decrease with the increase of height-width ratio; 4) The aspect ratio of grille has a hooping effects on the infilled concrete, which should be reasonably considered during design; 5) Compared with other parameters, the influence of concrete compressive strength is negligible. The conclusion from the parametric study might be utilized for engineering practice of GSPCW in future.
\end{abstract}

Keywords: Steel Plate Concrete Composite Shear Wall, DIANA Software, Finite Element Model Analysis, Seismic Behavior Research. 


\section{INTRODUCTION}

Steel plate concrete composite shear wall is a shear wall formed by arranging steel plates on one or both sides or inside of the concrete slab, and combining the two materials through shear nails or bolt tie rods on the steel plate. According to the different steel layout of steel plate concrete composite shear wall, it can be roughly classified into three types, single-sided steel plate concrete composite shear wall, double-sided steel plate concrete composite shear wall and embedded steel plate concrete composite shear wall [1]. Domestic and foreign scholars currently have conducted many researches on various steel plate concrete composite shear walls. The previous researches indicate that steel plate concrete composite shear wall has higher load carrying capacity, larger stiffness, better ductility and energy dissipation capacity $[3,4,5]$.

To further improve the seismic behavior of steel plate concrete composite shear wall, W. $\mathrm{Xu}$ [6] proposes grille-type steel plate concrete composite shear wall, which is consisted of steel faceplates, steel tie plates and infilled concrete. And W. Xu has conducted a series of researches in a certain degree.

The initial study about grille-type steel plate concrete composite shear wall is carried out by X. Guo [7]. He analyzes the influence of different factors on the seismic behavior of grilletype steel plate concrete composite shear wall with embedded corrugated steel plate through experimental research and numerical simulation. The results indicate that the out-of-plane deformation of steel plates on the both sides of the shear wall is restricted due to the existence of concrete slab and ties of corrugated steel plate, thereby improving the out-of-plane buckling resistance of steel plates in the shear wall. Then T. Xu [8] and S. Ye [9] further improve the structure of grille-type steel plate concrete composite shear wall to replace the embedded corrugated steel plate to single independent steel plate. They find the new type of the shear wall has good seismic performance.

The two-dimensional numerical model of the grille-type steel plate concrete composite shear wall (abbreviated as GSPCW) is established in DIANA based on the two shear walls in S. Ye [9]. And 18 GSPCW specimens with various design parameters are designed to systematically investigate the influence of design parameters on GSPCW, including steel ratio, axial load ratio, height-width ratio, aspect ratio of grille as well as concrete compressive strength. The conclusion will provide reference for engineering applications in future construction works.

\section{BRIEF DISCRIPTION OF PREVIOUS TESTS}

This paper selects two GSPCW specimens to verify the accuracy of the simulations. The details of the two walls and material properties are presented in S. Ye [9]. Figure 1 shows views of the shear wall and the material properties are listed in Table 1 . The tests were conducted at the Civil Engineering and Transportation Building in Jiulonghu Campus of Southeast University. The two walls had the same height-width ratio of 2.0 and the axial load ratio is the main design variable considered in the experiments. The thickness of steel faceplates and steel tie plates is 4 millimeters. The concrete grade is C40 and the steel grade is Q235B. The loading beam and foundation beam are reinforcement concrete beams. And there is a $\mathrm{H}$ steel beam embedded in foundation beam, which is used to improve the stiffness of foundation beam.

As shown in Figure 2, the test setup consists of bottom fixing device, out-of-plane support, vertical and horizontal loading device, and loading method adopts force and displacementcontrolled loading history. The vertical load is applied by a hydraulic jack, and a steel beam is placed on the top of loading beam to evenly distribute the vertical load. Before the formal ap- 
plication of horizontal load, the pre-load of horizontal load needs to be carried out to determine whether the loading equipment, connected equipment and data acquisition system are normal. Then the single-stage horizontal load is applied until the specimen yields. After specimen yields, displacement controlled multi-stage loading is applied until the horizontal capacity of the specimen decreases to $85 \%$ of the peak horizontal load.

\begin{tabular}{ccccccc}
\hline No. & $\begin{array}{c}\text { Wall dimension } \\
\mathrm{W} \times \mathrm{T} \\
(\mathrm{mm} \times \mathrm{mm})\end{array}$ & $\begin{array}{c}\text { Steel plate } \\
\text { thickness } \\
(\mathrm{mm})\end{array}$ & Steel channel & $\begin{array}{c}\text { Axial load } \\
\text { ratio }\end{array}$ & $\begin{array}{c}\text { Concrete } \\
\text { strength } \\
(\mathrm{MPa})\end{array}$ & $\begin{array}{c}\text { Steel plate } \\
\text { strength } \\
(\mathrm{MPa})\end{array}$ \\
\hline GSSW-1 & $1400 \times 160$ & 4 & {$[16$} & 0.1 & 26.6 & 263.2 \\
GSSW-2 & $1400 \times 160$ & 4 & {$[16$} & 0.4 & 26.6 & 263.2 \\
\hline
\end{tabular}

Table 1: Properties of two shear walls of previous test. [9]

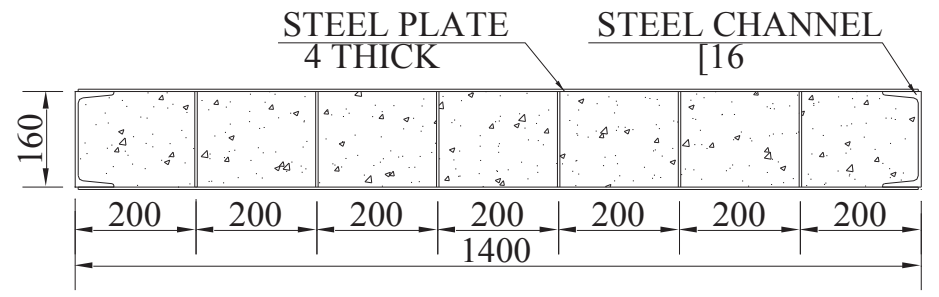

(a) Horizontal cross section

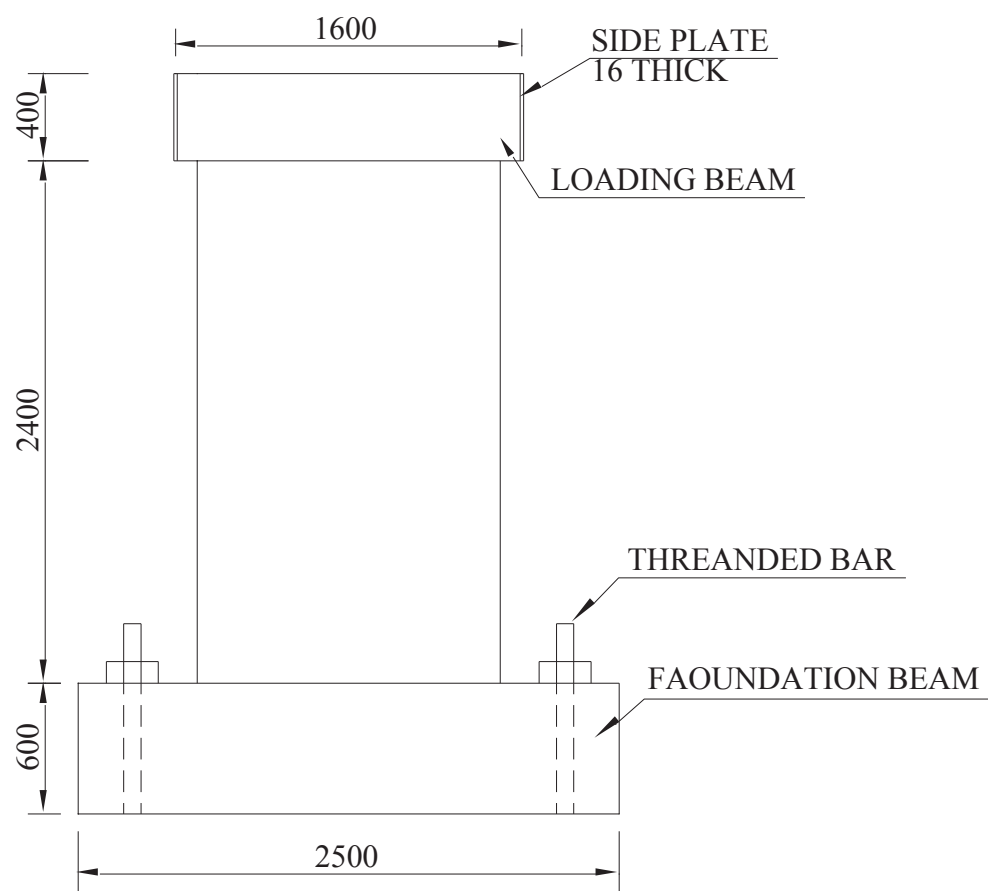

(b) Front view.

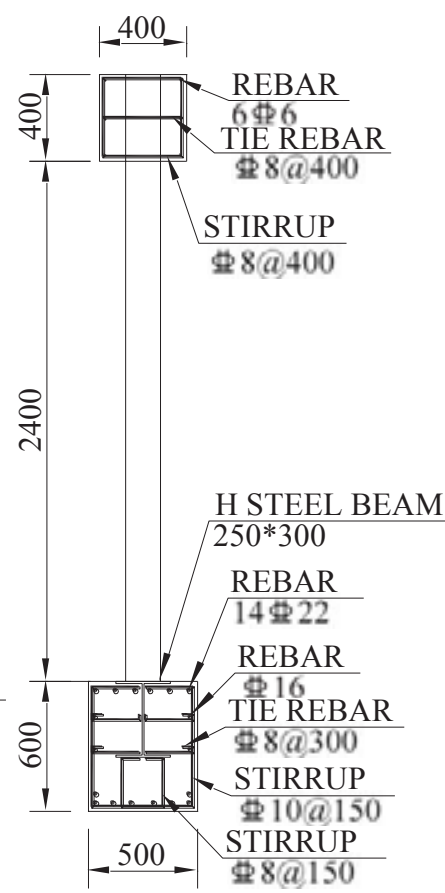

(c)Vertical cross section

Figure 1: Details of two shear walls of previous test. (Unit: mm, adapted from S. Ye [9]) 


\section{METHOD OF NUMERICAL SIMULATION}

\subsection{Modeling assumption}

Two-dimension simulation is adopted in this paper. Figure 3 presents the geometry of the GSPCW developed in DIANA. Eight-node quadrilateral isoparametric plane stress elements are used for the infilled concrete, steel faceplates, loading beam and foundation beam. Bar reinforcement elements are used for the steel tie plates. The size of all elements is $50 \mathrm{~mm}$. The translation of the bottom of the foundation beam is constrained.

The FE models are loaded in two steps as the same as the experiments: 1) the vertical load is applied to the top of the loading beam in a manner of uniform pressure, and 2) cyclic lateral displacement is applied to the centroid of loading beam.

The modified Newton-Raphson method is used for incremental-iterative solution. The convergence criteria combine force norm and displacement norm. Both physical nonlinear analysis and geometrical nonlinear analysis are considered in the analysis procedure.

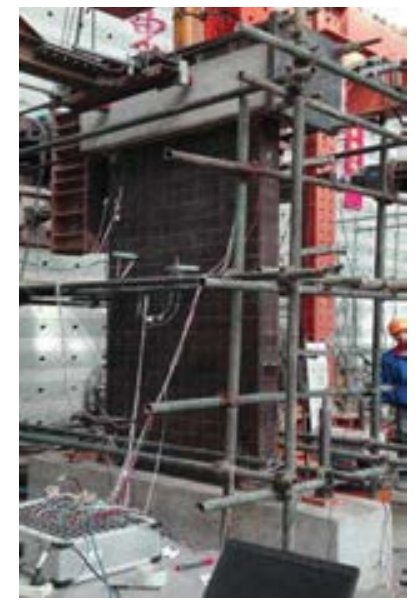

Figure 2: The loading process of GSSW-1.[9]

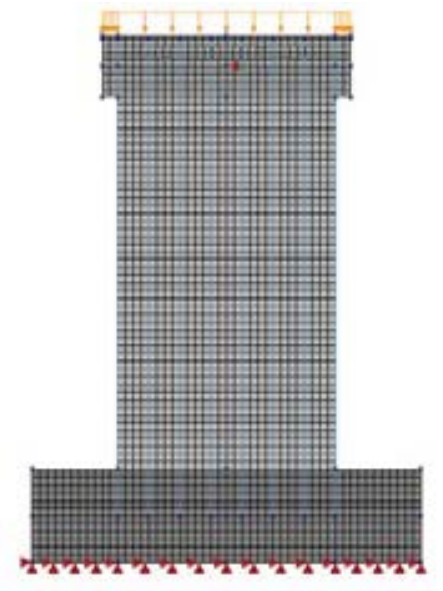

Figure 3: Model of GSPCW in DIANA.

\subsection{Material model}

The total strain crack model available in DIANA [10] is used for the infilled concrete. The input parameters for this model include linear material properties, crack direction and uniaxial behavior of concrete in compression and tension. The crack direction is rotating direction.

The uniaxial behavior of concrete is represented by a stress-strain curve, see Figure 4. In this paper, the constitute model of concrete in compression adopts the model proposed by $\mathrm{J}$. Mander et al. [11], which is applicable to both circular and rectangular shaped transverse reinforcement. The restraint effect of steel plates on concrete can be regarded as the restraint effect of many transverse reinforcements on concrete. The formula is as follows:

$$
\begin{gathered}
f_{c}=\frac{f_{c c}^{\prime} x r}{r-1+x^{r}} \\
x=\frac{\varepsilon_{c}}{\varepsilon_{c c}} \\
\varepsilon_{c c}=\varepsilon_{c o}\left\lfloor 1+5\left(\frac{f_{c c}^{\prime}}{f_{c o}^{\prime}}-1\right)\right\rfloor
\end{gathered}
$$




$$
\begin{gathered}
r=\frac{E_{c}}{E_{c}-E_{\mathrm{sec}}} \\
E_{\mathrm{sec}}=\frac{f_{c c}^{\prime}}{\varepsilon_{c c}}
\end{gathered}
$$

Where $f_{c c}^{\prime}$ is compressive strength of confined concrete, $\varepsilon_{c}$ is longitudinal compressive concrete strain, $f_{c o}^{\prime}$ and $\varepsilon_{c o}^{\prime}$ is the unconfined concrete strength and corresponding strain, $\varepsilon_{c o}^{\prime}$ can be assumed as $0.002, E_{c}$ is the tangent modulus of elasticity of the concrete, $E_{c}=5000 \sqrt{f_{c o}^{\prime}}$. The compressive strength of confined concrete $f_{c c}^{\prime}$ is determined by the confinement effectiveness for sections confined by steel plates and calculated according to the proposal of J. Cai [12].

The constitute model of concrete in tension is calculated according to CEB-FIP Model 1990 [13], and the formula is given by

$$
f_{t}= \begin{cases}0.26 f_{c u}^{2 / 3} & \left(f_{c u} \leq 50 M P a\right) \\ 0.21 f_{c u}^{2 / 3} & \left(f_{c u}>50 M P a\right)\end{cases}
$$

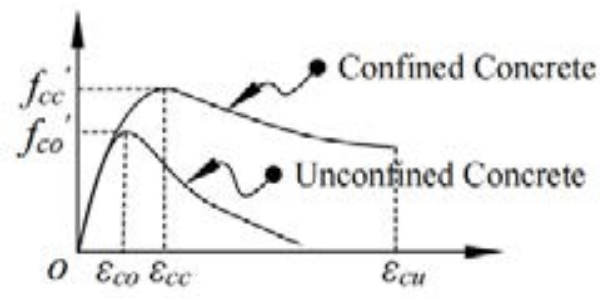

(a) Compression

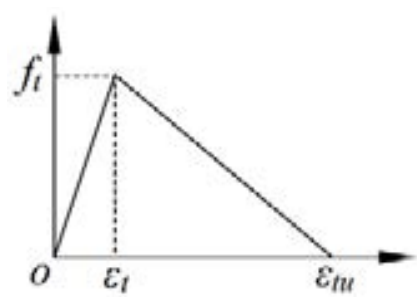

(b) Tension

Figure 4: Stress-strain relationship of concrete.

The constitute model of steel uses bilinear elastic hardening model. The elastic modulus, yield strength and ultimate strength are all base on the material properties tests. The Von Mises yield criterion is used to evaluate the yield status of steel.

\section{NUMERICAL RESULT AND VALIDATION}

Figure 5 is the load-displacement hysteric curves of GSSW-1 and GSSW-2. The experiment data of the hysteric curves is available in S. Ye [9]. And according to the hysteric curves, it is easy to calculate the skeleton curves and the rest of the relevant data, see Figure 6 Figure 9 and Table 2. It can be seen from Figure 5 and Figure 6 that the hysteric curves obtained from the numerical simulation are in good agreement with the skeleton curves. The magnitude of the peak load of the numerical simulation is larger than that of the test result, because the test specimens in actual situation have initial defects in a certain degree, and the bottom restraints of the test specimens cannot achieve the perfect effect of complete fixing. From the Figure 7, the stiffness of the FE model at the beginning of loading is greater than that of the experiment result. But as the loading continues, the difference between the two is getting smaller and smaller, because the constraints of the specimens in experiment are not as ideal as the constraints of FE model, so a certain error will occur at the beginning of loading, but as the loading displacement increases, the error caused by the constraint becomes more and more 
insignificant. From the perspective of energy consumption and equivalent viscous damping ratio, since the material in the finite element model is uniform and has no initial defects, the energy consumption capacity of the finite element model is stronger than that of the actual specimen.

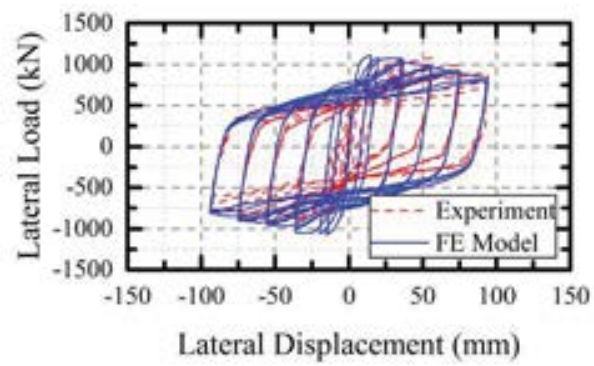

(a) GSSW-1

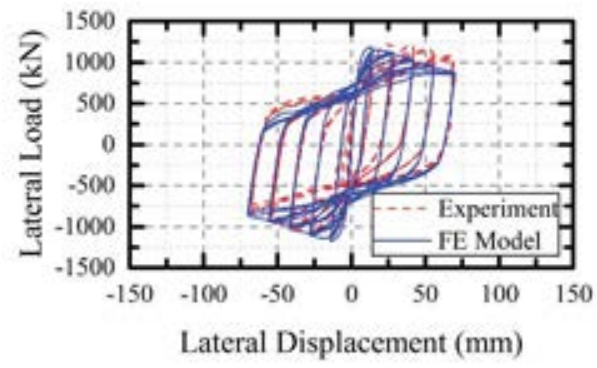

(b) GSSW-2

Figure 5: Comparison of load-displacement hysteric curves.

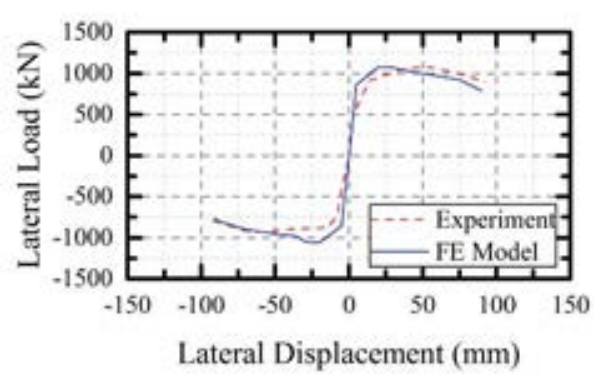

(a) GSSW-1

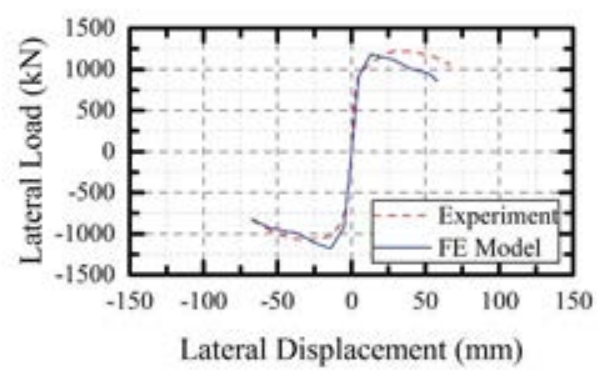

(b) GSSW-2

Figure 6: Comparison of load-displacement skeleton curves.

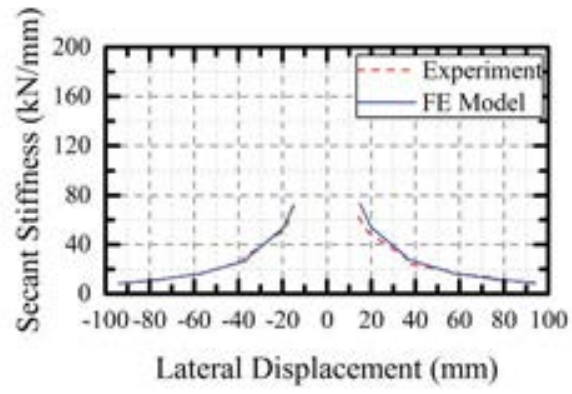

(a) GSSW-1

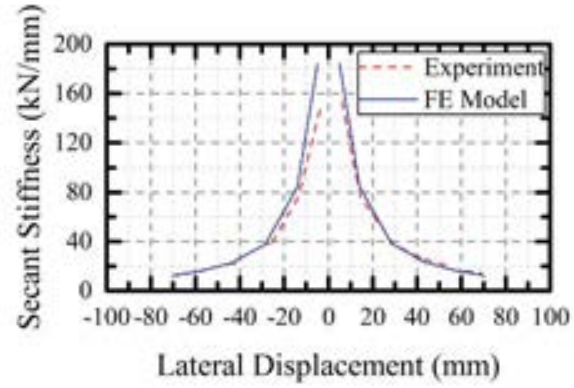

(b) GSSW-2

Figure 7: Comparison of secant stiffness degradation curves. 


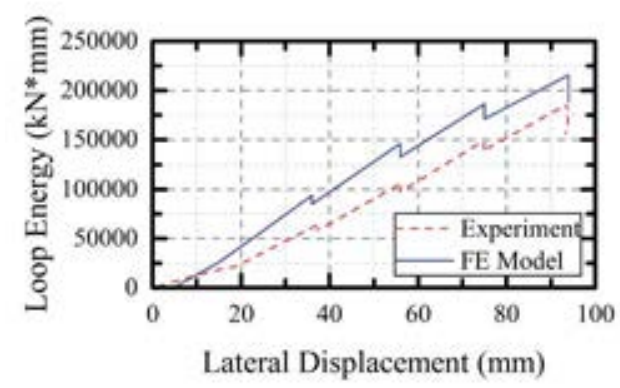

(a) GSSW-1

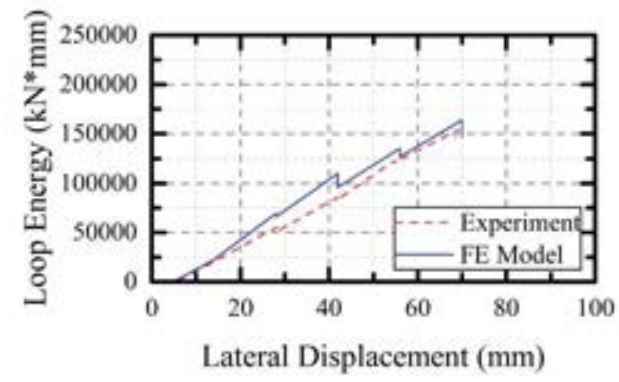

(b) GSSW-2

Figure 8: Comparison of energy dissipation curves.

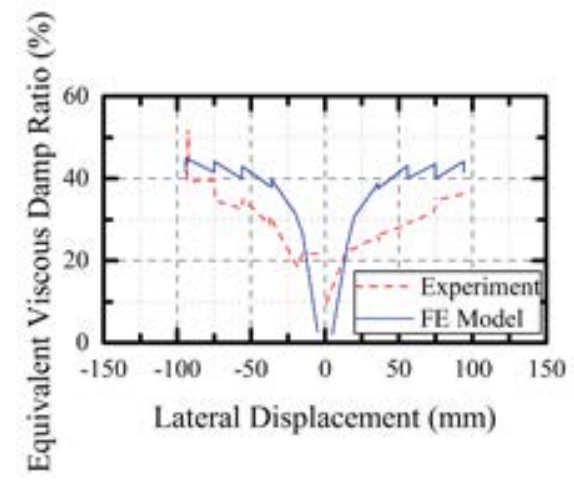

(a) GSSW-1

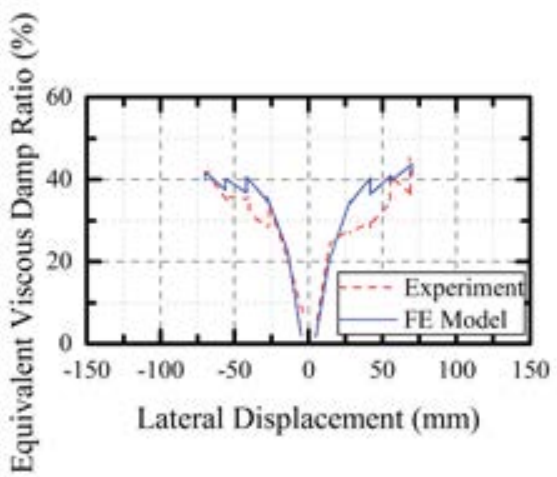

(b) GSSW-2

Figure 9: Comparison of equivalent viscous damp curves.

\begin{tabular}{cccccccc}
\hline No. & & $\begin{array}{c}\text { Loading } \\
\text { direction }\end{array}$ & $\begin{array}{c}F_{\mathbf{y}} \\
(\mathrm{kN})\end{array}$ & $\begin{array}{c}D_{\mathbf{y}} \\
(\mathrm{mm})\end{array}$ & $\begin{array}{c}F_{p} \\
(\mathrm{kN})\end{array}$ & $\begin{array}{c}D_{p} \\
(\mathrm{~mm})\end{array}$ & $\begin{array}{c}D_{u} \\
(\mathrm{~mm})\end{array}$ \\
\hline \multirow{3}{*}{ GSSW-1 } & \multirow{2}{*}{ Experiment } & + & 803.47 & 10.94 & 1079.54 & 52.90 & 92.60 \\
& & - & 840.59 & 13.10 & 930.00 & 55.40 & 91.90 \\
& \multirow{2}{*}{ FE model } & + & 898.69 & 7.75 & 1078.70 & 20.00 & 75.57 \\
& & - & 890.34 & 7.52 & 1060.00 & 20.00 & 91.00 \\
GSSW-2 & \multirow{2}{*}{ Experiment } & + & 931.24 & 4.81 & 1223.11 & 26.64 & 66.80 \\
& \multirow{2}{*}{ FE model } & - & 885.27 & 7.55 & 1070.00 & 26.40 & 60.04 \\
& & - & 1019.34 & 7.92 & 1190.00 & 13.00 & 40.07 \\
& & - & 1002.53 & 7.90 & 1180.00 & 14.00 & 35.73 \\
\hline
\end{tabular}

Notes: $F_{\mathbf{y}}$ and $F_{p}$ are respectively the horizontal capacity of specimen at yield point and peak point. $D_{\mathbf{y}}$, $D_{p}$ and $D_{u}$ are respectively the horizontal displacement of loading point of specimen at yield point, peak point and ultimate point. The ultimate point is the point at which the bearing capacity drops to $85 \%$ of the peak bearing capacity.

Table 2: Comparison of the features points of skeleton curves. 


\section{PARAMETRIC ANALYSIS}

In this study, a total of 18 shear walls were simulated, as shown in Table 3 . In the process of parametric analysis of numerical simulation, the values of material strength are taken in accordance with the "Code for Design of Concrete Structures" (GB50010-2010) [14] and "Code for Design of Steel Structures" (GB50017-2017) [15], and the rest of the parameter settings are shown in Section 3. The steel ratio is defined as the ratio of the cross-sectional area of the steel to that of the full cross-section of the specimen, and the steel ratio is reflected by the change of thickness of the steel faceplates and steel tie plates. The height-width ratio is defined as the ratio of the height from the top surface of the loading beam to the top surface of the ground beam to the section width of the member. The axial compression ratio is the ratio of the vertical load to the product of the axial compressive strength and the full cross-sectional area. The aspect ratio of the grille is the ratio of the spacing of the steel tie plates to the thickness of the wall.

\begin{tabular}{|c|c|c|c|c|c|c|c|}
\hline No. & $\begin{array}{c}\text { Wall dimension } \\
\mathrm{W} \times \mathrm{T} \\
(\mathrm{mm} \times \mathrm{mm})\end{array}$ & $\begin{array}{l}\text { Height- } \\
\text { width } \\
\text { ratio }\end{array}$ & $\begin{array}{l}\text { Concrete } \\
\text { grade }\end{array}$ & $\begin{array}{l}\text { Aspect } \\
\text { ratio of } \\
\text { grille }\end{array}$ & $\begin{array}{l}\text { Axial } \\
\text { load } \\
\text { ratio }\end{array}$ & $\begin{array}{l}\text { Steel } \\
\text { plate } \\
\text { thickness }\end{array}$ & $\begin{array}{l}\text { Steel } \\
\text { ratio }\end{array}$ \\
\hline GSPCW 1-1 & $1400 \times 160$ & 2.0 & $\mathrm{C} 40$ & 1.25 & 0.3 & 3 & $7.2 \%$ \\
\hline GSPCW1-2 & $1400 \times 160$ & 2.0 & $\mathrm{C} 40$ & 1.25 & 0.3 & 4 & $8.9 \%$ \\
\hline GSPCW 1-3 & $1400 \times 160$ & 2.0 & $\mathrm{C} 40$ & 1.25 & 0.3 & 5 & $10.5 \%$ \\
\hline GSPCW 1-4 & $1400 \times 160$ & 2.0 & $\mathrm{C} 40$ & 1.25 & 0.3 & 6 & $12.1 \%$ \\
\hline GSPCW2-1 & \multicolumn{7}{|c|}{ same as GSPCW1-2 } \\
\hline GSPCW2-2 & $1400 \times 160$ & 2.0 & $\mathrm{C} 40$ & 1.25 & 0.4 & 4 & $8.9 \%$ \\
\hline GSPCW2-3 & $1400 \times 160$ & 2.0 & $\mathrm{C} 40$ & 1.25 & 0.5 & 4 & $8.9 \%$ \\
\hline GSPCW2-4 & $1400 \times 160$ & 2.0 & $\mathrm{C} 40$ & 1.25 & 0.6 & 4 & $8.9 \%$ \\
\hline GSPCW2-5 & $1400 \times 160$ & 2.0 & $\mathrm{C} 40$ & 1.25 & 0.7 & 4 & $8.9 \%$ \\
\hline GSPCW3-1 & $1400 \times 160$ & 1.5 & $\mathrm{C} 40$ & 1.25 & 0.3 & 4 & $8.9 \%$ \\
\hline GSPCW3-2 & \multicolumn{7}{|c|}{ same as GSPCW1-2 } \\
\hline GSPCW3-3 & $1400 \times 160$ & 2.5 & $\mathrm{C} 40$ & 1.25 & 0.3 & 4 & $8.9 \%$ \\
\hline GSPCW3-4 & $1400 \times 160$ & 3.0 & $\mathrm{C} 40$ & 1.25 & 0.3 & 4 & $8.9 \%$ \\
\hline GSPCW3-5 & $1400 \times 160$ & 3.5 & $\mathrm{C} 40$ & 1.25 & 0.3 & 4 & $8.9 \%$ \\
\hline GSPCW4-1 & $1400 \times 160$ & 2.0 & $\mathrm{C} 40$ & 1.75 & 0.3 & 4 & $8.3 \%$ \\
\hline GSPCW4-2 & $1400 \times 160$ & 2.0 & $\mathrm{C} 40$ & 1.46 & 0.3 & 4 & $8.6 \%$ \\
\hline GSPCW4-3 & \multicolumn{7}{|c|}{ same as GSPCW1-2 } \\
\hline GSPCW4-4 & $1400 \times 160$ & 2.0 & $\mathrm{C} 40$ & 1.09 & 0.3 & 4 & $9.1 \%$ \\
\hline GSPCW5-1 & $1400 \times 160$ & 2.0 & $\mathrm{C} 30$ & 1.25 & 0.3 & 4 & $8.9 \%$ \\
\hline GSPCW5-2 & \multicolumn{7}{|c|}{ same as GSPCW1-2 } \\
\hline GSPCW5-3 & $1400 \times 160$ & 2.0 & $\mathrm{C} 50$ & 1.25 & 0.3 & 4 & $8.9 \%$ \\
\hline GSPCW5-4 & $1400 \times 160$ & 2.0 & $\mathrm{C} 60$ & 1.25 & 0.3 & 4 & $8.9 \%$ \\
\hline
\end{tabular}

Table 3: The main parameters of numerical models. 


\subsection{Steel ratio}

In this study, the change in the steel ratio of the specimens is reflected by the thickness change of the steel plate: the thicker the steel plates, the greater the steel ratio of the specimens. When the thickness of the steel plate is $3 \mathrm{~mm}$ to $6 \mathrm{~mm}$, the corresponding steel ratio of the specimen is $7.2 \%$ to $12.1 \%$. According to Figure 10 and Table 4, the research results show that the increase of the steel ratio can improve the bearing capacity and lateral stiffness of the shear wall. The lateral stiffness is defined as the ratio of the bearing capacity to the displacement at the yield point. When the thickness of the steel plate is increased from $3 \mathrm{~mm}$ to $5 \mathrm{~mm}$, the peak bearing capacity of the specimen is increased by $36.7 \%$, and the lateral stiffness is increased by $14.4 \%$. Because the axial load ratio of the model is relatively small, the lateral stiffness of the specimen is basically the full-section elastic stiffness, and the stiffness of the concrete section accounts for a relatively large amount. Therefore, the increase in the lateral stiffness of the specimen is smaller than the increase in the bearing capacity.

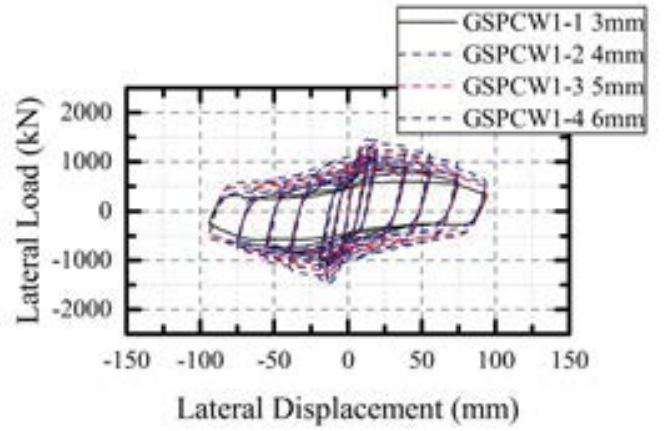

(a) Hysteric curves

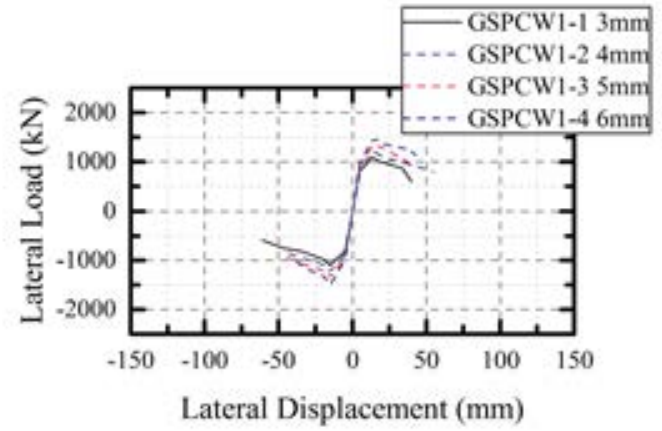

(b) Skeleton curves

Figure 10: Influence of steel ratio on hysteric curves and skeleton curves.

\begin{tabular}{ccccccc}
\hline No. & $\begin{array}{c}\text { Loading } \\
\text { direction }\end{array}$ & $\begin{array}{c}F_{\mathbf{y}} \\
(\mathrm{kN})\end{array}$ & $\begin{array}{c}D_{\mathbf{y}} \\
(\mathrm{mm})\end{array}$ & $\begin{array}{c}F_{y} / D_{y} \\
(\mathrm{kN} / \mathrm{mm})\end{array}$ & $\begin{array}{c}F_{p} \\
(\mathrm{kN})\end{array}$ & $\begin{array}{c}D_{u} \\
(\mathrm{~mm})\end{array}$ \\
\hline \multirow{2}{*}{ GSPCW1-1 } & + & 927.50 & 8.31 & 111.65 & 1086.68 & 27.32 \\
& - & 914.76 & 8.56 & 106.84 & 1096.87 & 24.23 \\
GSPCW1-2 & + & 1027.58 & 8.96 & 114.66 & 1221.49 & 28.38 \\
& - & 1025.83 & 9.22 & 111.28 & 1235.34 & 23.91 \\
GSPCW1-3 & + & 1142.42 & 9.47 & 120.59 & 1354.77 & 28.57 \\
& - & 1139.90 & 9.77 & 116.67 & 1370.54 & 23.92 \\
GSPCW1-4 & + & 1254.05 & 9.86 & 127.16 & 1480.34 & 36.01 \\
& - & 1257.48 & 10.25 & 122.73 & 1504.66 & 22.75 \\
\hline
\end{tabular}

Table 4: Influence of steel ratio on feature points of skeleton curves.

\subsection{Axial load ratio}

The variation range of the axial load ratio of the test specimens is 0.3 to 0.7 . The hysteric curves, skeleton curves and feature points are shown in Figure 11 and Table 5. It can be seen from the calculation results that when the axial load ratio is in the range of 0.3 to 0.7 , the horizontal bearing capacity estimated by finite element varies less, and the difference in the bearing capacity of the specimens is mainly due to the dispersion of material strength. It can also be seen from Table 5 that when the axial compression ratio is less than 0.5 , the lateral stiff- 
ness of the test specimen increases with the increase of the axial compression ratio. This is because the increase in axial load can delay the development of cracks, thereby improving the lateral stiffness of the specimen. However, when the axial compression ratio is greater than 0.5 , due to the large axial load, the specimen enters the plastic development stage in advance, which reduces the lateral stiffness of the specimen. In general, it is recommended that in actual projects, the axial load ratio of the GSPCW should be controlled below 0.5 to ensure its good seismic performance.

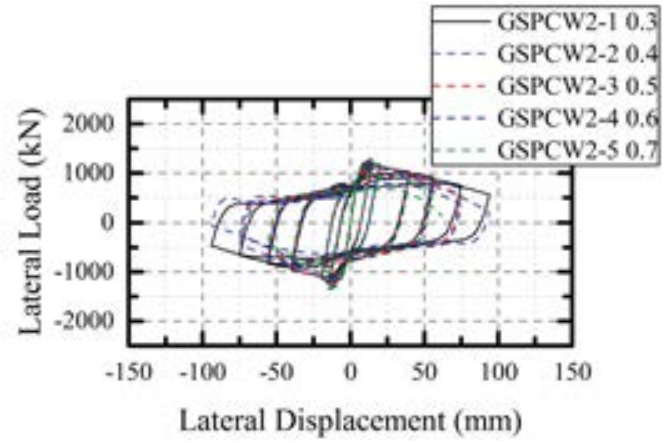

(a) Hysteric curves

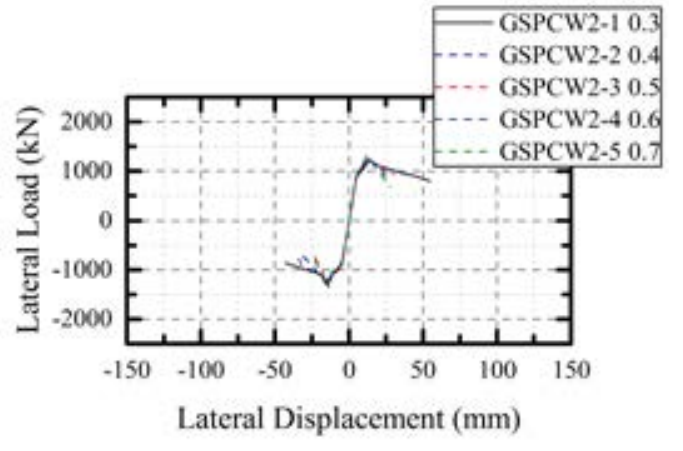

(b) Skeleton curves

Figure 11: Influence of axial load ratio on hysteric curves and skeleton curves.

\begin{tabular}{ccccccc}
\hline No. & $\begin{array}{c}\text { Loading } \\
\text { direction }\end{array}$ & $\begin{array}{c}F_{\mathbf{y}} \\
(\mathrm{kN})\end{array}$ & $\begin{array}{c}D_{\mathbf{y}} \\
(\mathrm{mm})\end{array}$ & $\begin{array}{c}F_{y} / D_{y} \\
(\mathrm{kN} / \mathrm{mm})\end{array}$ & $\begin{array}{c}F_{p} \\
(\mathrm{kN})\end{array}$ & $\begin{array}{c}D_{u} \\
(\mathrm{~mm})\end{array}$ \\
\hline \multirow{2}{*}{ GSPCW2-1 } & + & 1027.58 & 8.96 & 114.66 & 1221.49 & 28.38 \\
& - & 1025.83 & 9.22 & 111.28 & 1235.34 & 23.91 \\
GSPCW2-2 & + & 1054.41 & 9.04 & 116.68 & 1253.29 & 24.48 \\
& - & 1036.89 & 9.42 & 110.07 & 1274.51 & 20.78 \\
GSPCW2-3 & + & 1094.41 & 9.02 & 121.34 & 1280.58 & 21.23 \\
& - & 1081.76 & 9.41 & 114.93 & 1308.52 & 16.93 \\
GSPCW2-4 & + & 111.96 & 9.07 & 122.62 & 1300.54 & 19.15 \\
& - & 1055.32 & 9.76 & 108.08 & 1337.08 & 19.20 \\
GSPCW2-5 & + & 1141.93 & 8.94 & 127.66 & 1310.83 & 16.94 \\
& - & 997.94 & 10.17 & 98.16 & 1357.47 & 17.34 \\
\hline
\end{tabular}

Table 5: Influence of axial load ratio on feature points of skeleton curves.

\subsection{Height-width ratio}

The height-width ratio of the shear wall is one of the main factors that determines the failure type of shear wall and affects its seismic performance. The height-width ratio of the model studied in this paper ranges from 1.5 to 3.5. The hysteric curves, skeleton curves and characteristic points are shown in Figure 12 and Table 6. It can be seen from the calculation results that when the height-width ratio is increased from 1.5 to 3.5, its bearing capacity decreases by $58.3 \%$, and its lateral stiffness decreases by $87.6 \%$. The height-width ratio has a distinct effect on the bearing capacity and lateral stiffness of the shear wall. This is because as the height-width ratio increases, the failure mode of the specimen transitions from shear failure to bending failure, so the bearing capacity and lateral stiffness are reduced accordingly. When the height-width ratio is greater than 2.0, the bearing capacity and stiffness of the spec- 
imens change slightly with the increase of the aspect ratio, and the descending segment of the skeleton curves of the specimens tends to be flat at the post-stage of loading, and the ultimate displacement gradually increases.

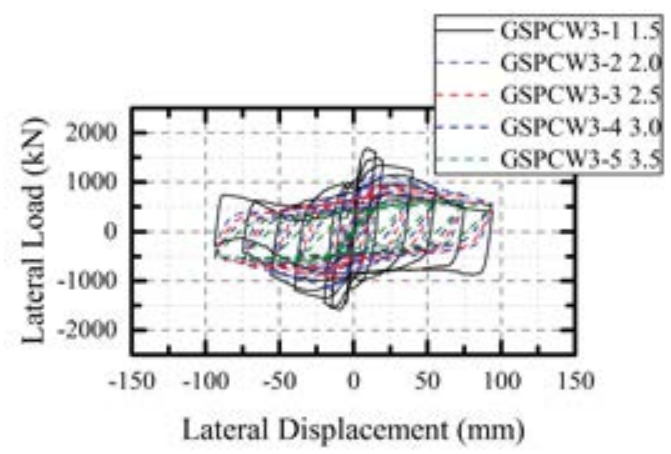

(a) Hysteric curves

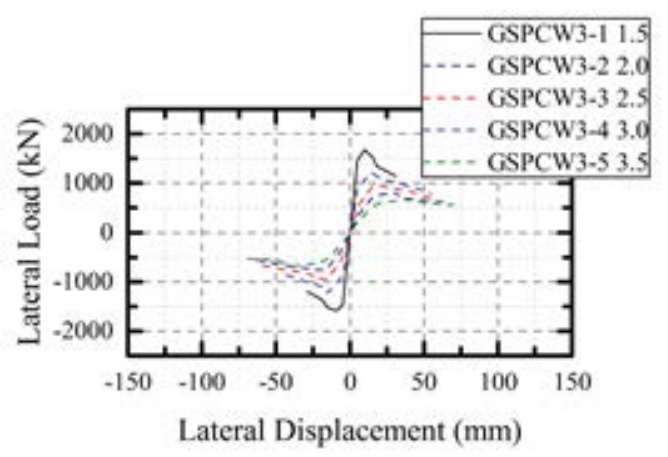

(b) Skeleton curves

Figure 12: Influence of height-width ratio on hysteric curves and skeleton curves.

\begin{tabular}{ccccccc}
\hline No. & $\begin{array}{c}\text { Loading } \\
\text { direction }\end{array}$ & $\begin{array}{c}F_{\mathbf{y}} \\
(\mathrm{kN})\end{array}$ & $\begin{array}{c}D_{\mathbf{y}} \\
(\mathrm{mm})\end{array}$ & $\begin{array}{c}F_{y} / D_{y} \\
(\mathrm{kN} / \mathrm{mm})\end{array}$ & $\begin{array}{c}F_{p} \\
(\mathrm{kN})\end{array}$ & $\begin{array}{c}D_{u} \\
(\mathrm{~mm})\end{array}$ \\
\hline \multirow{2}{*}{ GSPCW3-1 } & + & 1528.98 & 6.40 & 238.75 & 1680.45 & 16.93 \\
& - & 1488.94 & 5.78 & 257.42 & 1583.03 & 19.59 \\
GSPCW3-2 & + & 1027.58 & 8.96 & 114.66 & 1221.49 & 28.38 \\
& - & 1025.83 & 9.22 & 111.28 & 1235.34 & 23.91 \\
GSPCW3-3 & + & 852.24 & 12.97 & 65.73 & 969.34 & 41.54 \\
& - & 846.54 & 12.76 & 66.34 & 959.90 & 31.53 \\
GSPCW3-4 & + & 729.84 & 16.47 & 44.31 & 814.40 & 38.01 \\
& - & 717.52 & 15.41 & 46.55 & 770.74 & 45.68 \\
GSPCW3-5 & + & 602.80 & 19.70 & 30.59 & 682.39 & 43.83 \\
& - & 600.84 & 19.58 & 30.69 & 679.11 & 47.92 \\
\hline
\end{tabular}

Table 6: Influence of height-width ratio on feature points of skeleton curves.

\subsection{Aspect ratio of grille}

The aspect ratio of the grille refers to the ratio of the spacing of the steel tie plates to the thickness of the wall. It can be seen from Figure 13 and Table 7 that the aspect ratio of the grille has a certain influence on the seismic performance of the GSPCW. As the aspect ratio of the grille decreases, the horizontal bearing capacity of the specimens increases instead. This is because the steel faceplates and steel tie plates have a certain hoop effect on the filled concrete. When the aspect ratio of the grille increases, the bond between the steel faceplates and the inner concrete is weakened, which cannot effectively limit the out-of-plane deformation of the steel faceplate, so the hoop effect is relatively weakened. The displacements at yield points and ultimate points of the test specimens increase with the decrease of aspect ratio of grille, and the deformation performance of the test specimens have a certain improvement. 


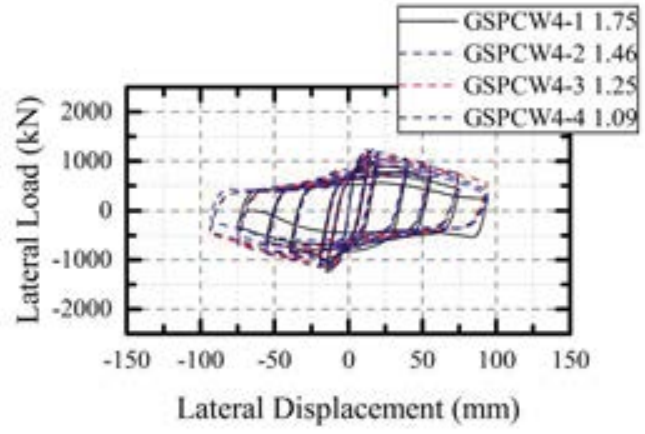

(a) Hysteric curves

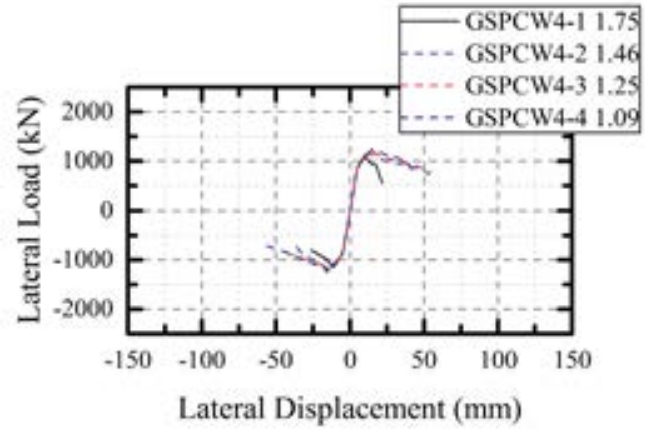

(b) Skeleton curves

Figure 13: Influence of aspect ratio of grille on hysteric curves and skeleton curves.

\begin{tabular}{ccccccc}
\hline No. & $\begin{array}{c}\text { Loading } \\
\text { direction }\end{array}$ & $\begin{array}{c}F_{\mathbf{y}} \\
(\mathrm{kN})\end{array}$ & $\begin{array}{c}D_{\mathbf{y}} \\
(\mathrm{mm})\end{array}$ & $\begin{array}{c}F_{y} / D_{y} \\
(\mathrm{kN} / \mathrm{mm})\end{array}$ & $\begin{array}{c}F_{p} \\
(\mathrm{kN})\end{array}$ & $\begin{array}{c}D_{u} \\
(\mathrm{~mm})\end{array}$ \\
\hline \multirow{2}{*}{ GSPCW4-1 } & + & 1008.72 & 7.79 & 129.54 & 1124.95 & 13.98 \\
& - & 997.85 & 8.01 & 124.55 & 1134.18 & 17.28 \\
GSPCW4-2 & + & 1025.63 & 8.50 & 120.65 & 1183.62 & 25.44 \\
& - & 1010.36 & 8.88 & 113.83 & 1200.99 & 24.10 \\
GSPCW4-3 & + & 1027.58 & 8.96 & 114.66 & 1221.49 & 28.38 \\
& - & 1025.83 & 9.22 & 111.28 & 1235.34 & 23.91 \\
\multirow{2}{*}{ GSPCW4-4 } & + & 1052.53 & 9.15 & 115.03 & 1250.68 & 31.93 \\
& - & 1049.23 & 9.40 & 111.58 & 1263.49 & 25.39 \\
\hline
\end{tabular}

Table 7: Influence of aspect ratio of grille on feature points of skeleton curves.

\subsection{Concrete compressive strength}

In this study, the compressive strength of concrete was selected to be changed from $30 \mathrm{MPa}$ to $60 \mathrm{MPa}$, and the calculation results are shown in Figure 14 and Table 8 . The results show that with the increase of concrete strength, the horizontal bearing capacity and lateral stiffness of the specimens have a certain increase, but the growth rate is small. This is because highstrength concrete has a higher elastic modulus. Compared with other research variables, the compressive strength of concrete has less influence on the seismic behaviors of GSPCW.

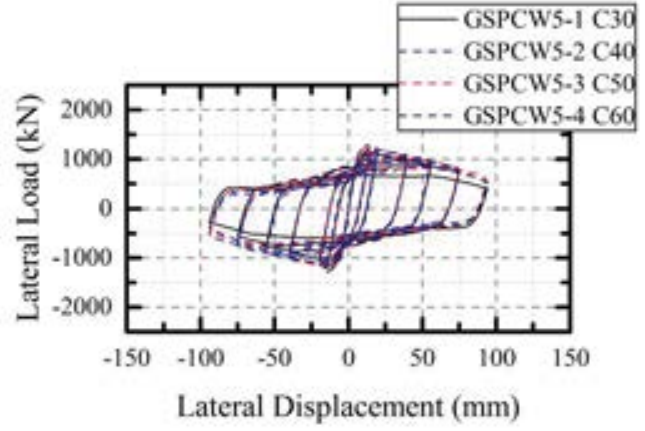

(a) Hysteric curves

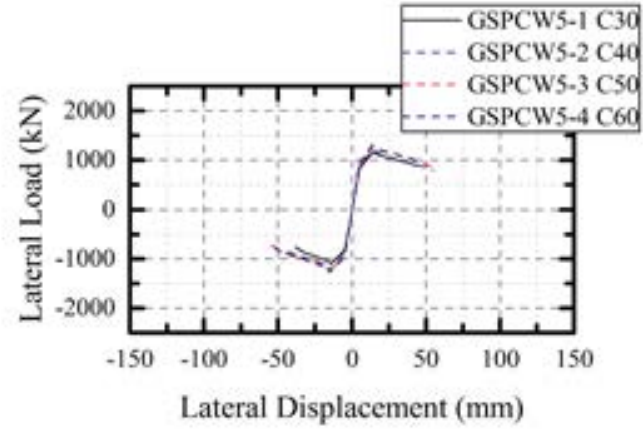

(b) Skeleton curves

Figure 14: Influence of concrete compressive strength on hysteric curves and skeleton curves. 


\begin{tabular}{ccccccc}
\hline No. & $\begin{array}{c}\text { Loading } \\
\text { direction }\end{array}$ & $\begin{array}{c}F_{\mathbf{y}} \\
(\mathrm{kN})\end{array}$ & $\begin{array}{c}D_{\mathbf{y}} \\
(\mathrm{mm})\end{array}$ & $\begin{array}{c}F_{y} / D_{y} \\
(\mathrm{kN} / \mathrm{mm})\end{array}$ & $\begin{array}{c}F_{p} \\
(\mathrm{kN})\end{array}$ & $\begin{array}{c}D_{u} \\
(\mathrm{~mm})\end{array}$ \\
\hline \multirow{2}{*}{ GSPCW5-1 } & + & 976.68 & 9.06 & 107.81 & 1160.86 & 32.47 \\
& - & 927.29 & 8.36 & 110.88 & 1099.01 & 26.52 \\
GSPCW5-2 & + & 1027.58 & 8.96 & 114.66 & 1221.49 & 28.38 \\
& - & 1025.83 & 9.22 & 111.28 & 1235.34 & 23.91 \\
GSPCW5-3 & + & 1068.95 & 8.92 & 119.80 & 1270.68 & 33.37 \\
& - & 1057.47 & 9.04 & 116.98 & 1272.84 & 24.41 \\
GSPCW5-4 & + & 1104.41 & 8.90 & 124.15 & 1312.81 & 30.16 \\
& - & 1080.64 & 8.90 & 121.46 & 1299.76 & 24.14 \\
\hline
\end{tabular}

Table 8: Influence of concrete compressive strength on feature points of skeleton curves.

\section{CONCLUTIONS}

This paper mainly studies the influence of different design variables on the seismic behavior of GSPCW, including steel ratio, axial load ratio, height-width ratio, aspect ratio of grille as well as concrete compressive strength. The DIANA software was used to establish the finite element models of GSPCW, and the accuracy of the model was verified based on the previous test data. A total of eighteen shear wall models with different design parameters were further established. By comparing their hysteric curves, skeleton curves and feature points, the following conclusions were drawn:

1) To increase the steel ratio of the section can significantly increase the horizontal bearing capacity of the component, and increase the lateral stiffness of the component to a certain extent;

2) When the axial load ratio of the shear wall is less than 0.5 , the bearing and deformation capacity will be improved with the increase of the axial load ratio. But when the axial load ratio is greater than 0.5 , the increase in the axial compression ratio is more unfavorable to the seismic performance of the specimens. Therefore, the axial load ratio of this type of shear wall below 0.5 is expected in actual projects.

3) As the height-width ratio of the shear wall increases, the failure mode of the shear wall gradually develops from shear failure to bending failure, and the bearing capacity and lateral stiffness of the component decrease rapidly.

4) The aspect ratio of the grille is a meaningful design parameter to determine the hooping effect of the steel plate on the infilled concrete. The smaller the aspect ratio of the grille, the stronger the constraint on the infilled concrete, so the concrete compressive strength is higher, thereby the horizontal bearing capacity of the specimen is developed. In the actual practice, the influence of the aspect ratio of the grille on the seismic performance of the component should be reasonably considered.

5) Compared with other design parameters, concrete compressive strength has little-to-no effect on the seismic performance of GSPCW. The horizontal bearing capacity and lateral stiffness of specimens improve slightly with the increase of concrete strength.

\section{REFERENCES}

[1] J. Nie, M. Tao, J. Fan, et al. Research advances of composite shear walls with double steel plates and filled concrete. Building Structures, 41(12), 52-60, 2011. (in Chinese) 
[2] W. Wang, Y. Wang, Z. Lu. Experimental study on seismic behavior of steel plate reinforced concrete composite shear wall. Engineering Structures, 160, 281-292, 2018.

[3] M. Ozaki, S. Akita, H. Osuga, et al. Study on steel plate reinforced concrete panels subjected to cyclic in-plane shear. Nuclear Engineering \& Design, 228(1/3), 225-244, 2004.

[4] K. Emori. Compressive and shear strength of concrete filled steel box wall. Steel Structures, 2(01), 29-40, 2002.

[5] R. Link, A. Elwi. Composite concrete-steel plate walls: Analysis and behavior. Journal of Structural Engineering, 121(02), 260-271, 1995.

[6] W. Xu, T. Xu. Seismic performance test of grille type double steel plate concrete composite shear wall. Journal of Architecture and Civil Engineering, 35(02), 111-118, 2018. (in Chinese)

[7] X. Guo. Study on seismic behavior of grid-type steel tube-concrete composite shear walls. Southeast University. Nanjing, 2016. (in Chinese)

[8] T. Xu. Experimental study on grille-type steel plate concrete composite shear wall under low cyclic loading. Southeast University. Nanjing, 2017. (in Chinese)

[9] S. Ye. Study on seismic performance of concrete filled steel tube frame-grille type steel plate shear wall structure. Southeast University. Nanjing, 2018. (in Chinese)

[10] DIANA. User's manual - DIANA Documentation Release 10.3. Version 10.3, 2019.

[11] J. Mander, M. Prestley, R. Park. Theoretical stress-strain model for confined concrete. American Society of Civil Engineers, 114(08), 1804-1826,1988.

[12] J. Cai, G. Sun. Constitutive relationship of concrete core confined by square steel tube. Journal of South China University of Technology, 36(01), 105-109, 2008. (in Chinese)

[13] CEB-FIP Model 1990. Model code for concrete structures (1990): chapter 2: material properties. Lausanne, 1991.

[14] GB 50010-2010, Code for design of concrete structures. China Architecture \& Building Press, Beijing, 2015. (in Chinese)

[15] GB 50017-2017, Standard for design of steel structures. China Architecture \& Building Press, Beijing, 2017. (in Chinese) 